\title{
Argininemia as a cause of severe chronic stunting in a low-resource developing country setting: a case report
}

\author{
Nora King ${ }^{1 *}$, Romina Alvizures ${ }^{1,2}$, Pablo García ${ }^{1}$, Ann $_{\text {Wessel }}^{3}$ and Peter Rohloff ${ }^{1}$
}

\begin{abstract}
Background: Argininemia is rare inborn error of metabolism which, when untreated, presents in late infancy with growth delay and developmental regression. In developed countries, argininemia is diagnosed early by newborn screening and is treated immediately with a protein-restricted diet. In developing countries, diagnosis may be delayed by the assumption that stunting is related to malnutrition alone.
\end{abstract}

Case presentation: We describe the diagnosis and treatment of argininemia in a 60-month-old Kaqchikel Maya girl in rural Guatemala. The patient initially presented with severe stunting and developmental regression. The initial diagnosis of argininemia was made by a screening test in dried blood spots and confirmed with urine and serum amino acid profiles. The patient was treated with a low-protein diet using locally available foods, leading to significant improvement in her growth and development.

Conclusions: This case demonstrates that the identification, diagnosis and treatment of IEM in developing countries are increasingly feasible, as well as ethically imperative. Providers working with malnourished children in developing countries should suspect IEM in malnourished children who do not respond to standard therapies.

Keywords: Argininemia, Inborn errors of metabolism, Stunting, Child development, Resource-poor medicine

Abbreviations: ALT, Alanine aminotransferase; AST, Aspartate aminotransferase; IEM, Inborn error of metabolism; TSH, Thyroid-stimulating hormone; UCD, Urea cycle disorder

\section{Background}

Argininemia (OMIM \#207800), an autosomal recessive disorder of the urea cycle, is caused by a deficiency in the activity of the hepatic arginase enzyme (ARG1). It is thought to be among the rarest of the urea cycle disorders (UCD), with a global incidence of 1 in 2 million births [1]. Unlike the other UCD, argininemia does not typically present with neonatal or early childhood hyperammonemia. Rather, the disorder emerges between 1 and 4 years of age, characterized by slowing linear growth and failure of regular cognitive development [2, 3]. Episodic hyperammonemia may occur, but usually does not lead to lifethreatening acute illness. If untreated, argininemia can

\footnotetext{
* Correspondence: nora@wuqukawoq.org

'Wuqu' Kawoq | Maya Health Alliance, 2a Calle 5-43 Zona 1, Santiago

Sacatepéquez, Guatemala

Full list of author information is available at the end of the article
}

cause loss of developmental milestones, spastic diplegia, and severe intellectual disability.

In developed countries, the early diagnosis of nonproximal UCD is accomplished by tandem mass spectrometry (MS/MS) newborn screening [4]. However, in most developing countries, these techniques are unavailable. Additionally, the exceedingly high prevalence of chronic undernutrition, as well as the relative lack of access to pediatricians, may lead to a failure to consider inborn errors of metabolism (IEM) in the differential diagnosis of growth disorders. Here we report on a case of argininemia diagnosed in a 5-year-old female of Kaqchikel Maya ethnicity in rural Guatemala who previously carried a diagnosis of chronic severe malnutrition. Her diagnosis was aided by international partnerships. We discuss the unique challenges of managing argininemia in a rural, under-resourced setting. 


\section{Case presentation}

A 60-month-old female presented to our clinic in central Guatemala after developmental delay since late infancy and developmental regression for 1 year. At this time, her weight was $9.0 \mathrm{~kg}$ and height was $86.3 \mathrm{~cm}$. According to the World Health Organization growth standards, her height-for-age Z-score was -4.9 and her weight-forheight Z-score was -3.0, consistent with severe wasting and severe stunting [5].

The patient was born at term at home following an uneventful pregnancy. She had never seen a physician, but was evaluated by several community health workers and received presumptive community-based therapy for undernutrition. She is of Kaqchikel Maya descent and was born in an isolated village in Guatemala. Her parents were first cousins; there was no family history of severe childhood illness or death. She exhibited progressive delay in attaining motor milestones; although she sat independently (5 months) and crawled (10 months) in a timely fashion, she did not walk until 2 years. Language and social development were delayed, and she exhibited only vocalizations and gestures without meaningful word acquisition. She never attained bladder or bowel sphincter control. She had no acute severe childhood illnesses, and received all routine vaccinations according to the national schedule. She was exclusively breastfed until 1 year of age. Upon initiation of complementary feeding, she showed a clear aversion to animal protein and vomited on the rare occasions that she consumed it. At 4 years of age, 1 year before presentation to our clinic, the patient ceased walking, adopted a flexed posture of both lower extremities with scissoring and rigidity, and restrictive eating lead to significant weight loss. The patient's physical exam was notable for severe under-nutrition, and lower extremity hypertonicity and spasticity. When supported in a standing position, she exhibited scissoring and a "tip-toe" posture. Babinski reflexes were upgoing bilaterally. She demonstrated an attentive gaze and social smile, but was nonverbal. Her hair was lighter and coarser than that of family members. Dietary recall revealed extremely low energy consumption $(52 \mathrm{kcal} / \mathrm{kg} /$ day) with low-normal protein intake $(0.93 \mathrm{~g} / \mathrm{kg} /$ day $)$ exclusively from plant sources. The family followed the advice of community health workers to provide dietary supplements, including iron, vitamin B12 and fortified corn-soy blends, but felt ambivalent about the treatments' effectiveness.

Blood chemistry showed borderline elevations of lactic acid $(3.3 \mathrm{mmol} / \mathrm{L}$, reference range $0.7-2.1 \mathrm{mmol} / \mathrm{L})$ and ammonia (87.9 ug/dL, reference range 18-90 ug/dL). AST (aspartate aminotransferase) and ALT (alanine aminotransferase) were $38 \mathrm{IU} / \mathrm{L}$ and $50 \mathrm{IU} / \mathrm{L}$, respectively. TSH (thyroid-stimulating hormone), uric acid, blood urea nitrogen, creatinine, bilirubin, serum electrolytes, and complete hematologic profile were uninformative. A filter paper blood spot was obtained and transported to the United States by courier. Analysis was conducted by Perkin Elmer Genetics laboratory (Bridgeville, PA). The analysis revealed an elevated arginine level of $3.05 \mathrm{mg} / \mathrm{dL}$ (reference range $<2.00 \mathrm{mg} / \mathrm{dL}$ ). On a repeat blood spot, arginine was again elevated at $2.04 \mathrm{mg} / \mathrm{dl}$. Subsequently serum and urine samples submitted to the Biochemical Genetics Laboratory at the Mayo Clinic (Rochester, MN) for confirmatory testing. Results were remarkable for serum arginine of $510 \mathrm{nmol} / \mathrm{mL}$ (reference range $31-132$ $\mathrm{nmol} / \mathrm{mL}$ ) and urine orotic acid of $46 \mathrm{mmol} / \mathrm{mol}$ of creatinine (reference range undetectable), findings consistent with a biochemical diagnosis of argininemia.

The mainstay of treatment for argininemia is a protein-restricted diet [6]. This presents a substantial challenge in rural Guatemala, where poverty and food availability prevent many families from providing adequate nutrition for healthy children, much less for special needs diets. Additionally, there is no access to protein-free or essential amino acid medical foods or ammoniascavenging medications. Corn tortillas, the staple of the Maya Guatemalan diet, provide $200 \mathrm{kcal}$ and $5.4 \mathrm{~g}$ protein per $100 \mathrm{~g}$ [7]. At even fairly nominal levels of consumption, tortillas would easily exceed recommended daily protein restrictions for a UCD [8]. The family expressed concern about the cost of other low-protein, high-calorie foods. In collaboration with the patient's family, we developed a customized diet based on locally available food stuffs, principally oat or corn porridge and affordable fruits and vegetables. Refined sugar and vegetable oil were used to augment calories, since these were affordable to the family. This diet provided $110 \mathrm{kcal} / \mathrm{kg} /$ day and 1.5 $\mathrm{g} / \mathrm{kg} /$ day of locally available protein. For the first 4 weeks following the patient's diagnosis, a Kaqchikel Maya-speaking social worker specializing in child nutrition made weekly visits to review dietary intake.

On this nutritional regimen, she gained $3.3 \mathrm{~kg}$ in the first 6 months, and her weight-for-height Z-score improved to -0.9. Importantly, the patient regained developmental milestones. Six months following her diagnosis, the patient was able to turn completely while lying, support her torso from a prone position and stand briefly while supporting herself. Before treatment, she was completely immobile. The patient's family reported her to be increasingly interactive, and at 6 months basic verbal language returned. Dietary adherence was very good and the family quickly learned to differentiate high- and low-protein foods. Several 24-h diet recalls demonstrated an average of $94 \mathrm{kcal} / \mathrm{kg} /$ day and $1.4 \mathrm{~g} / \mathrm{kg} /$ day of intact protein.

\section{Conclusions}

Here we present a case of late diagnosis of argininemia in a severely stunted and wasted Maya child in Guatemala. 
Diagnostically, this represented a challenge because of the Guatemala's endemic stunting, particularly among the rural, indigenous population to which our patient belongs. Indeed, rural indigenous Guatemalan children are likely the most stunted population in the world [9]. Because stunting and chronic undernutrition increase susceptibility to infectious disease, severely stunted children commonly present with acute wasting [10]. Furthermore, severely stunted children can manifest significant cognitive delays and late attainment of motor function $[11,12]$. For these reasons, initial attempts by community health workers to treat this patient for the common malnutrition syndromes were not unreasonable. However, several features of the patient's presentation, including the loss of developmental milestones, progressive spastic diplegia, and highly restrictive eating habits with protein avoidance, were inconsistent with primary malnutrition, prompting us to initiate a more thorough medical evaluation. In addition, her stunting was striking even in comparison to cohorts of other poor, Maya children, who averaged $102.2 \mathrm{~cm}$ at 5 years [13]. This highlights the need for protocol- and community-based approaches to child malnutrition in developing countries-potentially in the form of "warning signs" checklists-to better train frontline workers on indications for deviating from protocol and seeking a higher level of care.

The treatment for argininemia requires dietary protein restriction while providing adequate nitrogen and energy for optimal growth. We did not have access to essential amino acid medical foods that typically complement a low-protein diet to provide total daily protein intake at or below recommendations for age. In addition, we were unable to monitor plasma amino acids to evaluate dietary adherence, and extreme poverty limited access to higher-quality protein. We instituted a mild protein restriction of 1 to $1.5 \mathrm{~g}$ protein $/ \mathrm{kg}$, emphasizing complementary vegetable proteins (e.g., beans and corn). This diet was financially acceptable to the patient's family, and actually increased the child's pretreatment protein intake to promote catch-up growth, prevent catabolism, and provide essential amino acids.

Confirming the diagnosis of an IEM in a developing country is challenging given the lack of laboratories that conduct newborn screening and esoteric confirmatory testing. Guatemala's two largest public hospitals, located in the capital, have small in-house screening programs for detecting congenital hypothyroidism, phenylketonuria, congenital adrenal hyperplasia, and galactosemia only [14]. Our experience offers insight into ways to improve diagnosis and management of UCDs in resourcepoor settings. Given the stability of filter paper blood samples, we suggest that international processing in a reference laboratory with extended newborn screening capabilities is a rapid, cost-effective mechanism for advancing the diagnostic workup of children in whom metabolic illness is suspected. We acknowledge that confirmatory testing remains problematic and expensive, especially when scarce funds must be allocated to provide the most societal benefit. However, when evaluating severe presentations of long-standing malnutrition in a referral center such as ours, there is an important need to reconsider the clinical presentation and available data and to broaden the differential diagnosis and workup where resources allow. We suggest that global health practitioners working with children with complex medical illnesses should consider building capacity for collecting, transporting, and processing filter paper specimens.

Finally, the diagnosis and management of IEM in developing countries is frequently assumed to be logistically and financially untenable. Indeed, the medical foods and ammonia-scavenging medications typically used in managing UCDs are not available where we work, nor are laboratory tests for monitoring plasma amino acids. However, our patient had a remarkable clinical response to simple nutritional therapy, including careful total protein restriction with global calorie augmentation using economical local foods. Her case underscores the inestimable benefit of case management and nutrition in under-resourced, global health contexts.

\section{Consent}

Verbal informed consent in Kaqchikel Maya was obtained from the patient's mother and grandmother, her legal guardians. Verbal consent was deemed to be more ethical than written because the guardians do not speak Spanish or English and cannot read or write. This was done in accordance with the medical organization's Statement on Informed Consent in Minority Groups (available upon request). The interpreter who participated in the consent signed a witness statement agreeing that it was performed in accordance with ethical principles (also available upon request).

\section{Acknowledgements}

We thank the personnel of the Biochemical Genetics Laboratory at Mayo Clinic for performing and interpreting the confirmatory testing and Dr. Piero Rinaldo for covering the cost of the analyses using the T. Denny Sanford professorship fund.

\section{Funding}

No funding was obtained for the writing and publication of this manuscript. The non-governmental organization described in the manuscript provided medical care free of charge to the subject.

Availability of data and materials

The data used for this case study, beyond generally available academic publications, belong in a confidential medical record and is not publically available.

Authors' contributions

NK and PR drafted the manuscript and provided clinical care to the patient. RA and PG critically revised the manuscript and provided clinical care to the patient. AW critically revised the manuscript and assisted in the formulation 
of the nutritional plan for the patient. All authors read and approved the final manuscript.

\section{Competing interests}

The authors declare that they have no competing interests.

\section{Consent for publication}

please see "Consent to participate and Ethics approval." More information available on request.

\section{Ethics approval and consent to participate}

The guardians of the patient discussed in this manuscript verbally agreed to the patient's case study being written and potentially published. As these guardians did not speak or write Spanish, verbal consent was deemed more ethical than written consent. Essential concepts of informed consent (that agreement to participate would not be remunerated, that declining to participate would result in no change in care or punitive action, and that the patient's anonymity would be preserved) were explained in appropriate terms. The Spanish-Kaqchikel interpreter and witness for this consent signed a witness statement declaring that agreement was obtained ethically. This study was not submitted to an IRB, but subject consent and writing of the paper was carried out in a manner consistent with Wuqu' Kawoq's Statement on Informed Consent in Minority Groups. These documents are available upon request to author NK.

\section{Author details}

'Wuqu' Kawoq | Maya Health Alliance, 2a Calle 5-43 Zona 1, Santiago Sacatepéquez, Guatemala. ${ }^{2}$ Facultad de Medicina, Universidad Francisco Marroquín, 6a Avenida 7-55 zona 10, Guatemala City 01010, Guatemala. ${ }^{3}$ Metabolism Program, Boston Children's Hospital, 300 Longwood Ave, Boston, MA 02115, USA.

Received: 4 June 2015 Accepted: 6 August 2016

Published online: 22 August 2016

\section{References}

1. Scaglia F, Lee B. Clinical, biochemical, and molecular spectrum of hyperargininemia due to arginase I deficiency. Am J Med Genet C Semin Med Genet. 2006;142C:113-20.

2. Wong D, Cederbaum S, Crombez EA. Arginase Deficiency. In: Pagon RA, Adam MP, Ardinger HH, Wallace SE, Amemiya A, Bean LJ, Bird TD, Fong C-T, Mefford HC, Smith RJ, Stephens K, editors. GeneReviews ${ }^{\oplus}$. Seattle: University of Washington; 2004.

3. Brusilow SW. Urea Cycle Enzymes. In: Scrivner CR, editor. The Metabolic \& Molecular Bases of Inherited Disease. 8th ed. New York: McGraw-Hill, Medical Publishing Division; 2005. p. 1909-63.

4. Jay A, Seeterlin M, Stanley E, Grier R. Case Report of Argininemia: The Utility of the Arginine/Ornithine Ratio for Newborn Screening (NBS). JIMD Rep. 2013:9:121-4.

5. WHO. WHO | The WHO Child Growth Standards. Geneva: World Health Organization; 2015.

6. Iyer R, Jenkinson CP, Vockley JG, Kern RM, Grody WW, Cederbaum S. The human arginases and arginase deficiency. J Inherit Metab Dis. 1998;21 Suppl 1:86-100.

7. Tabla de Composición de Alimentos de Centroamérica [http://www.incap. int/biblio/index.php/es/publi-a-la-venta/843-tabla-de-composicion-dealimentos-de-centroamerica2]

8. Singh $\mathrm{RH}$. Nutrition management of patients with inherited disorders of urea cycle enzymes. In: Acosta PB, editor. Nutrition Management of Patients with Inherited Metabolic Disorders. Sudbury, MA: Jones and Bartlett, 2010. Print; 2010. p. 405-30.

9. Black RE, Victora CG, Walker SP, Bhutta ZA, Christian P, de Onis M, Ezzati M, Grantham-McGregor S, Katz J, Martorell R, Uauy R. Maternal and child undernutrition and overweight in low-income and middle-income countries. Lancet. 2013;382:427-51.

10. Katona P, Katona-Apte J. The interaction between nutrition and infection. Clin Infect Dis. 2008:46:1582-8.

11. Kulkarni S, Ramakrishnan U, Dearden KA, Marsh DR, Ha TT, Tran TD, Pachón H. Greater length-for-age increases the odds of attaining motor milestones in Vietnamese children aged 5-18 months. Asia Pac J Clin Nutr. 2012;21:241-6.
12. Wu L, Katz J, Mullany LC, Haytmanek E, Khatry SK, Darmstadt GL, West KP, LeClerg SC, Tielsch JM. Association between nutritional status and positive childhood disability screening using the ten questions plus tool in Sarlahi, Nepal. J Health Popul Nutr. 2010;28:585-94.

13. Bogin B, Smith P, Orden AB, Varela Silva MI, Loucky J. Rapid change in height and body proportions of Maya American children. Am J Hum Biol. 2002;14:753-61.

14. Duarte Acuña A, Velsásquez Picot, D Coronado Herrera C, Soto García C. Evaluación Del Funcionamiento Del Area de Tamizaje Neonatal Del Hospital San Juan de Dios Durante El Año 2005 Al 2009. Guatemala City: Universidad de San Carlos de Guatemala, Facultad de Ciencias Químicas y Farmacia; 2011

\section{Submit your next manuscript to BioMed Central and we will help you at every step:}

- We accept pre-submission inquiries

- Our selector tool helps you to find the most relevant journal

- We provide round the clock customer support

- Convenient online submission

- Thorough peer review

- Inclusion in PubMed and all major indexing services

- Maximum visibility for your research

Submit your manuscript at www.biomedcentral.com/submit 